\section{Precio y calidad de los fondos mutuos de acciones chilenas}

Por Fernando López

-Ph.D. en Finanzas, Olin Business School, Universidad de Wh
Académico FEN.

Un fondo mutuo accionario es un panaturales y juridicas que se invierte en acciones nacionales 0 internacionales. Estos fondos ofrecen una alternativa para inversionistas que tienen un nivel de toleranci al riesgo relativamente alto y un horizonte de inversión de largo plazo. Una de sus principales ventajas es que permiten invertir en portafolios (o grupos) de varias acciones sin la necesidad de gestionar la inversión en cada una de ellas. Esta gestión está a cargo de expertos en finanzas que implementan estrategias de inversión con el objetivo generar rentabilidades elevadas con un nive muchos fondos mutuos accionarios no queen la mejor opción de rentabili dad y riesgo. Debido a su conocimiento de la economia, instituciones y cultura del país en que operan, uno esperaría que los administradores de fondos mutuos entreguen las mejores alternativas de inversión a través de sus fondos accionarios nacionales. Sin embargo una de las observaciones más populares trigantes en materia de inversiones es que cuerdo a su exposición al riesgo de mercado y que esta rentabilidad disminuye con los costos de administración. En resumen, en los uiltimos 5 años, la industria de fondos mutuos accionarios nacionales ha tenido un cia internacional.

¿ESTAMOS EN PRESENCIA DE UNA FALLA DE MERCADO?

No necesariamente. Existen al menos tres hipótesis por las cuales los inversionistas no y no toman los fondos mutucs bursatiles tos ta primara es que su nive más baramiento sobre las alternativas de inversión que tienen disponibles es muy bajo. En este contexto, las administradoras de fondos mutuos extraen rentas de los inversionistas induciéndolos a tomar fondos mutuos más caros. Una segunda alternativa es que los inversionistas valoran atributos más allá de la rentabilidad y riesgo. Algunos ejemplos son asesoría integral que acomoda los intereses y circunstancias personales de los inversionistas, la comodidad de tener más $d$ un mismo servicio financiero con la misma empresa y la confianza y tranquilidad para invertir en activos financieros que no eninstas bién. De esta manera, los inversioextra por sus fondos mutuos. Una terera explicación son las expectativas optimistas en que los inversionistas conocen la información histórica pero apuestan a que su ondo mutuo tendrá un desempeño que compensará los costos.

Entender el rol de cada una de estas hipótesis es un insumo clave para el perfeccionamiento de la regulación del mercado financiero. Si el problema es la falta de conocimiento, deberiamos pensar en una combinación de educación financiera con una reducción de la complejidad de la manera

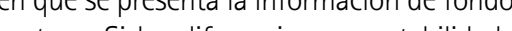
resgo se las diferenclas en rentabilidad cado segmentado en que los inversionistas y loren atributos más allé de la rentabilids y exposición al riesgo de sus inversiones, tienen expectativas optimistas acerca de su desempeño, entonces no estariamos necesariamente en presencia de una falla de mercado. A la fecha no existen estudios para e mercado chileno que nos permitan distinguir ntre estas alternativas.

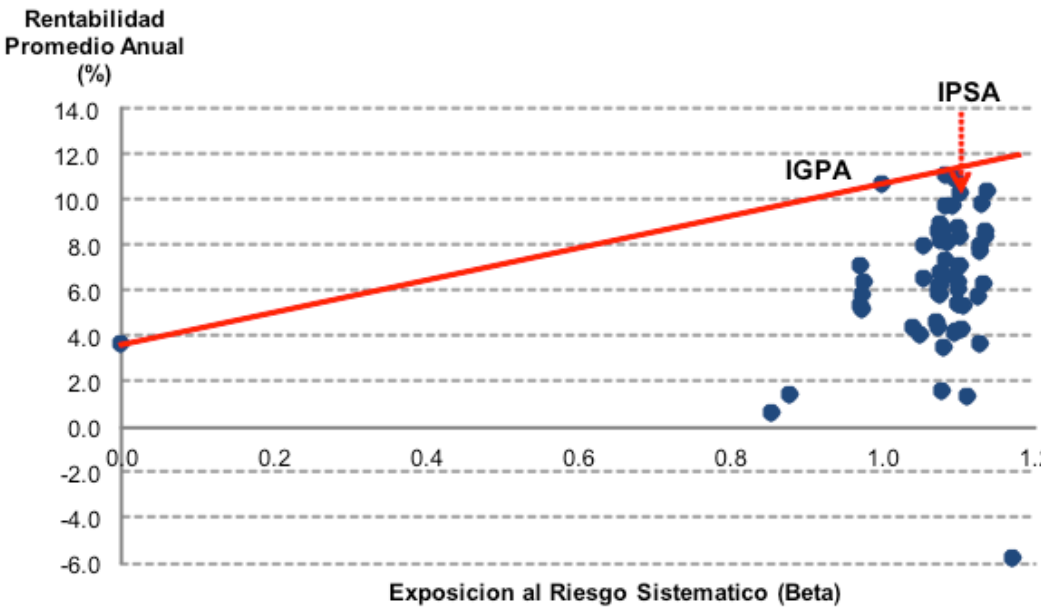

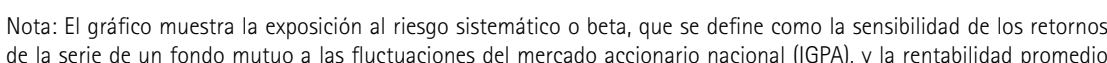
mensual anualizada de los valores cuota de las 55 series de fondos mutuos accionarios nacionales vigentes en el periodo 2009-2013.

Gráfico 2: Costo vs desempeño de fondos mutuos de acciones Chilenas (2009-2013)

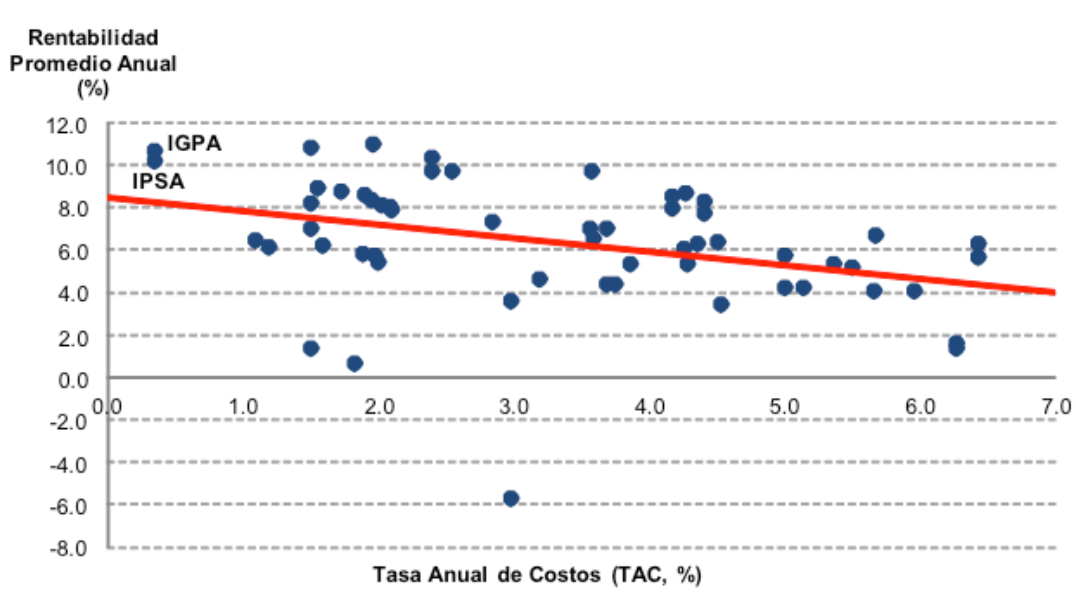

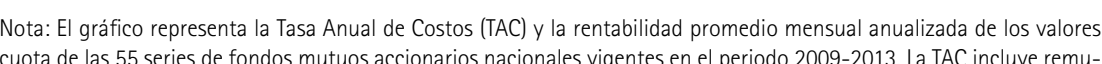

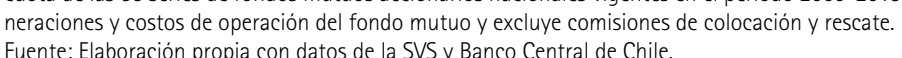

Gráfico 3: Costo vs desempeño de fondos mutuos de acciones Chilenas (2009-2013)

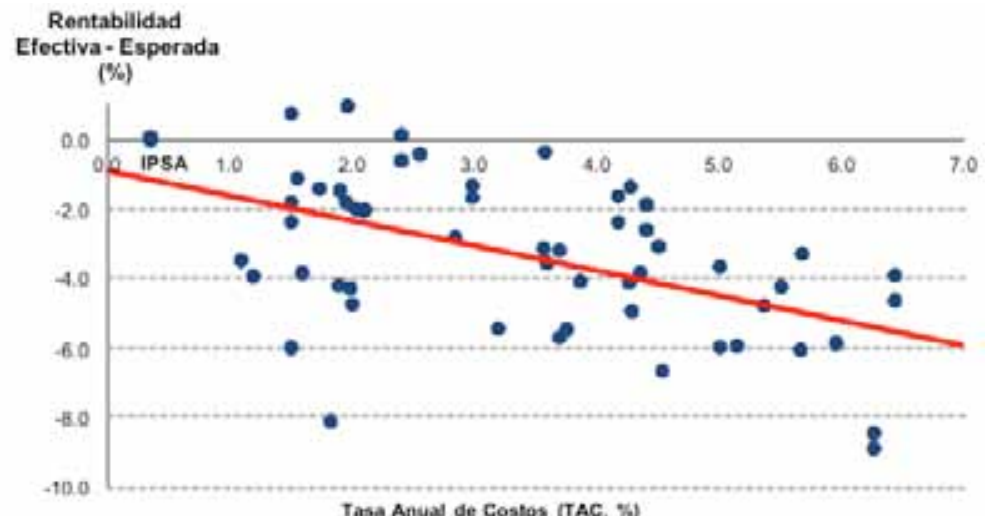

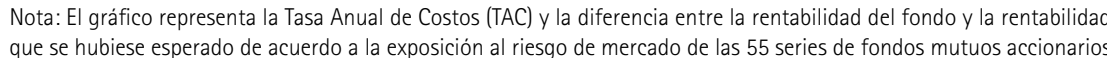

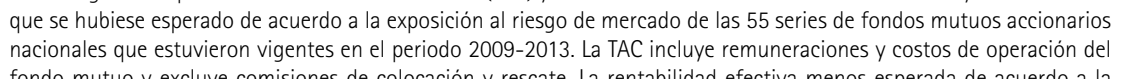
fondo mutuo y excluye comisiones de colocación y rescate. La rentabilidad
exposición al riesgo sistematico se conoce técnicamente como Affa de Jensen 